\title{
Comparing the General Foundation Programme's English Teachers' Beliefs and Practices Regarding Written Corrective Feedback in an Omani EFL Context
}

\author{
Dr. Soufiane Trabelsi \\ The General Foundation Programme \\ Sohar University \\ Oman
}

\begin{abstract}
The current study investigated written corrective feedback (WCF) in the General Foundation Programme (GFP) in one of the Omani private universities. This paper, which is based on a doctoral research study, will focus only on three research questions: (a) what are the writing teachers' beliefs with regard to WCF? (b) What are their practices with regard to WCF? (c) To what extent do the teachers' beliefs and practices regarding the provision of WCF on the students ' writing align? The participants of the study were a sample of writing teachers and some of their students. Semi-structured interviews, classroom observations, student focus groups and student text analysis were used as research instruments. The study revealed both congruence and incongruence between the teachers' beliefs and practices. Some implications, which might be useful for writing teachers and researchers in WCF and teacher cognition, are put forward.
\end{abstract}

Keywords: Written corrective feedback, EFL, writing, beliefs, practices, congruence, incongruence

\section{Introduction}

Academic writing is fundamental to students' academic survival at the tertiary level education, yet at the same time, it is the most difficult skill to master. It is not a given skill even for students whose first language is English. This is because these students still need to learn and adhere to the specialised language and conventions of the academic discourse, and to interact with the several contextual factors that are found in their institutions although they are highly competent in their linguistic abilities. In the case of ESL/EFL contexts, academic writing becomes an even more demanding skill because it requires that students have the knowledge of their disciplines in addition to the linguistic competence to express this knowledge in a manner appropriate to their disciplines' communities of practice. Having said that, Oman is no exception in the challenge of preparing students to acquire the required academic writing skills to cope with the university studies and academic duties. To train and teach students to write correctly entails giving them effective and appropriate feedback. Thus, teaching academic writing and providing WCF on it are essential for students and for teachers. This is at the heart of the current study. A related aspect to WCF is teachers' beliefs and practices with regard to WCF. That is to say, it is important to know how feedback is viewed by teachers, how they deal with it practically, and the extent to which their views affect their practices. The main aim of the researcher is to investigate the notion of WCF in the Omani GFP context. He intends to explore how WCF is carried out by teachers and to compare what teachers think and do regarding it. All this is to be discussed in line with the latest literature and research on WCF. In a word, the current research project aims to make sure that WCF is made in the appropriate ways that suit the Omani EFL context and that it fulfils the role expected from it. The present study aims to address and find answers to the following research questions:

1-What are the GFP writing teachers' beliefs with regard to WCF?

2-What are their practices with regard to WCF?

3-To what extent do the teachers' beliefs and practices regarding the provision of WCF on the students' writing align? 


\section{Literature Review}

The researcher firmly believes that the exploration of the teachers' beliefs and practices with regard to the importance of the role of WCF constitutes an essential source of information to improve foreign and second language learning and teaching. The factors that influence the teachers' beliefs and practices regarding WCF will be also focused on in the present paper.

\subsection{Feedback in the teaching of ESL/EFL writing}

The role, importance, and effect of feedback in ESL or EFL have been key issues in several studies in the teaching of writing (Paltridge, 2004; Reichelt, 1999). Feedback on student writing can make learning more effective as noted by Cardelle and Corno (1981). The more feedback students receive on their performance, the better they understand what they need to do to correct their mistakes. The understanding of why they made mistakes and how to correct such mistakes helps students correct their mistakes and increase their achievement (Kulhavy, 1977). Student writers who receive feedback will have information about which parts of their texts need to be corrected and improved. Carless (2006) confirms that students who receive feedback during the writing process have a clearer sense of how well they are performing and what they need to do to improve. Feedback can also modify students' thinking or behaviour toward their work and focus their attention on the purpose of writing. Furthermore, feedback can provide assessment on how well the students perform their work or their accomplishment of a given task (Schwartz \& White, 2000) as feedback is meant for helping students narrow down or close the gap between their actual ability and the desired performance (Brookhart, 2003).

\subsubsection{Written corrective feedback}

Two main categories of WCF can be identified: direct and indirect feedback. Direct corrective feedback is referred to as a type of correction that draws students' attention to the error and provides a solution to it. That is to say, the teacher shows students where their errors are and corrects these errors by providing the correct form. As for indirect corrective feedback, it means drawing students' attention to the locations of their errors without providing corrections (Bitchener \& Ferris, 2012). With regard to direct corrective feedback, it can take a variety of forms such as a) cross-outs: when the teacher omits any wrong addition from students' original texts, b) rewrites: when the teacher rewrites a word, phrase or a sentence, providing the correct spelling, structure or form on students' original texts, and c) additions: when the teacher adds any missing items on students' original texts (e.g. prefix, suffix, article, preposition, word, etc). As demonstrated by Bitchener and Ferris (2012), direct corrective feedback aims to help students edit their writing and improve their performance in future tasks. Furthermore, Ferris (2002) contends that this type of feedback is beneficial in dealing with errors of prepositions and other issues of idiomatic lexis. For her, this is helpful in the final stages of the writing process to help students focus on the remaining errors in their texts and refer to them in future tasks. Students' linguistic proficiency is vital to know the amount of direct corrective feedback they receive as advanced learners are more likely to benefit from it.

As far as indirect corrective feedback is concerned, it means underlining, circling or highlighting errors on students' original texts, indicating the location of these errors without correcting them. Students are required to study their errors and correct them (Ferris, 2002). Simply put, indirect corrective feedback lays emphasis on the role of students in understanding and correcting their errors rather than being given or shown the corrections.In underlining the writing errors, the students should understand that there is a problem that should be 'fixed.' This can take the form of using lines, circles or highlighting to indicate the location of errors. It is up to the teachers to decide how explicit indirect feedback should be based depending on the goals they want to achieve by providing feedback.

\subsection{Literature on teachers' beliefs and practices regarding WCF}

For the purpose of the present study, the researcher refers to teachers' beliefs as a set of assumptions, values, knowledge, feelings, and attitudes that might be consciously held by writing teachers, which are evaluative in nature and which can be expressed in the statement of what "should be done", and what "is preferable" in teaching writing, in general and in giving WCF on students" writing, in particular. This definition is adopted from (Borg, 2011) because it covers all major terms (e.g. thoughts, assumptions, feelings, knowledge, attitudes, values and ideas) used by researchers to define the term and because it emphasises the difference between "what should be done" (i.e. teachers' beliefs) and what is really done (i.e. teachers" practices), thus considering beliefs as a guide to teacher practice, and also highlighting the interrelationship between beliefs and practices. 
Not many studies have investigated teachers' beliefs and practices with regard to teacher written feedback and also studied the alignment between them. Among the few studies in this research area is Lee's (2004) study which aimed to investigate teachers' beliefs and practices related to error correction. Lee's findings revealed that the teachers in her study preferred the comprehensive approach, which aligned with their correction of almost all errors in the given task.

Another finding was that a majority of the teachers stated that they preferred using direct feedback, which also aligned with their practices in the correction task in which about $65 \%$ of the errors were corrected in this way. Another study which was undertaken by Montgomery and Baker (2007) comparing teachers' beliefs and practices with regard to written feedback indicated that the teachers' practices of giving written feedback were very different compared to their beliefs as reported in the questionnaires. The teachers' practices were different from their beliefs and from what they were instructed to do in their weekly meetings.

\subsubsection{The importance of studying beliefs and practices}

The late 1980s and 1990s witnessed an important step in teacher thinking research which was the study of teachers' beliefs. Researchers (e.g. Borg, 1999a, 1999b, 2006; Lin et al., 1999; Pajares, 1992) began to assign more importance to the study of beliefs not only with regard to their influence on behaviours but also regarding their improvement of teachers' professional development and practices. As a result, there was a shift from considering teaching as the application of predetermined principles and rules to a thinking activity where teachers construct their own workable and personal theories of teaching (Borg, 2003). As argued by Phipps and Borg (2009: 381), while beliefs serve as filters through which teachers interpret new experiences and information, they are not always manifested in what teachers do inside their classrooms. Consequently, studies about teachers ${ }^{6}$ beliefs emphasised the importance of studying teachers" practices through their beliefs as "a more realistic understanding of the relationship between teachers' beliefs and practices can emerge when the analysis of what teachers do is the basis of eliciting and understanding the beliefs" (Phipps \& Borg, 2009: 382). This indicates that when teachers' beliefs are elicited through their practices (e.g. by means of classroom observations), this will provide researchers with a view of what beliefs are (i.e. in reality) rather than what they could be (i.e. ideally) which can illuminate us more about teachers and teaching instead of having a theoretical description of what teachers believe and know (Borg, 2006: 273).

\subsubsection{The relationship between teachers' beliefs and their classroom practices}

The relationship between beliefs and practices has been a matter of interest of many researchers (e.g., Andrews, 2003; Borg, 2006; Kennedy \& Kennedy, 1996; Karavas-Doukas, 1996). This relationship has been identified as a highly complex one, neither linear nor causal (Fang, 1996), but rather dialectic (Clark \& Peterson, 1986), symbiotic (Foss \& Kleinsasser, 1996) and interactive. It is argued that although teachers' beliefs influence what teachers do in the classroom, teacher classroom practices are not always reflected in their stated beliefs (Almarza, 1996). Simply put, the teachers' actual practices do not manifest their stated beliefs (Kennedy \& Kennedy, 1996; Karavas-Doukas, 1996; Richards, 1996). Therefore, two conflicting findings can be identified which are consistency and inconsistency (i.e. match or mismatch / congruence and incongruence) found in the literature with regard to the relationship between beliefs and practices in general (Fang, 1996). Whereas some studies (Johnson, 1992; Bai \& Ertmer, 2008; Farrell \& Kum, 2008) referred to a congruent relationship between teachers ${ }^{6}$ beliefs and practices, other studies (Christ \& Makarani, 2009; Hiep, 2007; Philips \& Borg, 2009) identified incongruence between teachers' beliefs and their practices. For example, Mori (2002), who employed qualitative data in investigating two ESL teachers' corrective feedback behavior, found that teachers offer corrective feedback in accordance with their beliefs. In another study, Farrell and Kun (2008) explored three primary teachers' beliefs and practices in Singapore about the teachers' role in providing feedback and correcting students when they used Singlish in English classrooms. Their findings showed that the teachers' conceptions were mostly manifested in their practices. In contrast to the congruence between beliefs and practices in the two studies presented above, Basturkmen (2012) reviewed several empirical studies within this topic and found that there was some discrepancy between teachers' beliefs and their practices.

\subsubsection{Factors influencing teachers' beliefs and practices.}

Congruence or incongruence between teachers' beliefs and practices can be attributed to different factors. Magno and Amarles (2011: 21) argued that previous research on feedback stated that teachers' feedback practices are not just dictated by the perceived difficulties or needs of the students in their writing classes but also by the existing 
external factors such as teachers' beliefs on feedback, cultural, and institutional contexts, among others. Factors related to the institutional context concern large classes, mandated syllabus, instructional materials, insufficient instruction time, institutional requirements, scheduling, pressure of the exams and the culture (e.g. Feryok, 2008; Lu, 2003; Hiep, 2007). The cultural system that teachers work in has a great impact on their practices as well (Kennedy, 1988). Hyland and Hyland (2006: 10), who explored teacher written feedback in L2 writing, maintained that "like all acts of communication, (feedback) occurs in particular cultural, institutional and personal contexts, between people enacting and negotiating particular social identities and relationships, and is mediated by various types of delivery." In other words, feedback is closely related to the context where it is received and given. There are three more related contextual factors which are the time limitations, the need to cover the syllabus/text-books, and the heavy teaching loads.

Teacher-related factors can have an impact on teachers' beliefs and practices. These factors consist of the effect of the previous learning and teaching experiences, the lack of training, and lack of subject-specific knowledge. Borg (2003) argued that knowledge of the subject, personal knowledge, academic background, and practical experience can greatly affect teachers' beliefs and practices. In addition to the above, student-related factors, such as maintaining student discipline in class, oblige teachers sometimes to change their practices. Phipps and Borg (2009: 385) argued that teachers need to control discipline in the classroom and how this could cause incongruence between teachers' beliefs and practices.

As can be seen from the studies reviewed above, although some research already dealt with teachers' related WCF beliefs and practices, still little is known about the extent to which teachers' WCF beliefs are reflected in their actual practices. Therefore, the present study intends to contribute to the literature related to relationship between the teachers' beliefs and practices regarding WCF in ESL/EFL contexts, in general, and in an Omani setting, in particular.

\section{Methods}

The present study is mostly a qualitative research as it aims at exploring and describing the beliefs of writing teachers about their practices of WCF. Its main goal is to understand and present the teachers' experiences, attitudes, what meanings they give to their actions, and how they get along in a particular setting. This study took place in a natural setting, at a private university, with the purpose of describing phenomena (i.e. the writing teachers' beliefs about giving WCF and their actual practices and the extent to which the two aligned) as they occurred naturally (i.e. while teachers were correcting students papers and while they were providing feedback). The study employed multiple qualitative methods which were teacher semi-structured interviews (to elicit their beliefs and practices about the use of WCF), student focus groups (to evaluate their teachers' practices of WCF), unstructured classroom observations (to observe the teachers' actual practices while correcting their students writing and to see if their beliefs and practices aligned), and a feedback analysis of the students' papers (to explore the teachers' actual practices of the use of WCF).

The reason for employing qualitative methods is that quantitative methods do not give the teachers the chance to reflect on their ideas but rather the ideas of the researcher are imposed on the teachers, which in turn leads to an "etic" rather than "emic" perspective on beliefs (Munby, 1984). In addition, qualitative methods enable researchers to check for any misinterpretation of the teachers' views (Richards, 2003). Borg (1998a: 34), who explored L2 teachers' beliefs and practices regarding grammar teaching, concluded that qualitative methods allow for a large amount of descriptive data to be collected. He argued that "descriptive data allow phenomena to be analysed and represented in a form closer to participants " perceptions of reality than a qualitative data do".

\subsection{Data Collection}

The researcher observed the teachers' WCF practices before interviewing them so that he would not influence them (this was also based on his readings in the research methodology literature such as Al-Adawi, 2010; Mubarak, 2013; Alkhatib, 2015) and mainly to generate more valid data because if teachers were interviewed first, they might change their practices in the classroom observations or adjust their practices based on the questions and the ideas discussed in the interviews. Student focus groups were also employed after finishing the teacher interviews. The last step was student text analysis which took place after collecting some sample student writing portfolios via the teachers. 


\subsubsection{Sampling}

The participants in this study consisted of a sample of GFP teachers $(n=9)$ and a sample of their students $(n=75)$. The most important criteria for selecting the teacher participants were the following: the teachers were all teaching writing at the GFP for at least two years, and that they were teaching the writing course for preintermediate and intermediate students at the time of the study. All of the 9 teachers (women, $n=5 ;$ men, $n=4$ ), who were teaching writing at the period of collecting the data, were selected on the basis of the above mentioned criteria plus their willingness to participate in the study. The participants differed in their age, qualification, level of experience, national backgrounds, and their first language as there were six non-Arabic teachers. As far as the student participants were concerned, the researcher asked each of the nine teacher participants to find five volunteering students from their classes bearing in the mind that there should be high-achievers, average, and low- achievers among the students. Therefore, 15 groups of students making a total of 75 students expressed their willingness to participate in the study. Most of the students shared the same nationality (i.e. Omani), first language (Arabic), level of education (i.e. three pre-intermediate and 12 intermediate groups), but there were three Sudanese and two Egyptians. After they were approached by their teachers and after expressing their willingness to participate, they accepted to be interviewed.

\subsection{Data Analysis}

In the current study, the researcher used thematic analysis as the analytic lens to interpret the data of the teacher interviews and the student focus groups. Braun and Clarke (2006: 79) define thematic analysis as "a method for identifying, analysing, and reporting patterns (themes) within the data. For the observations, the researcher used an unstructured type where all the details of the WCF class were mentioned (the teacher, the class section, the students' level, the date, the time, the duration, the title of the feedback lesson, the number of observation, and what happened during the feedback session). Each teacher was observed twice. All the observation sheets (18) collected from the nine teachers were handled in the same way as the teacher and student focus group interview transcribed data. In other words, for consistency and validity purposes, the same codes and sub-codes were used in order to extrapolate information to answer the research questions. Regarding the last research instrument, namely, the student text analysis, students' writing texts were obtained after collecting their writing portfolios from the teachers. All the portfolios included practice paragraphs and essays, first and second draft assessment papers (i.e. continuous assessment writing quizzes). Some practice papers were marked by teachers and included feedback, whereas some papers were not marked and did not include any feedback points at all. For practical reasons, the researcher analysed only 10 texts from each of the nine teachers and the sample texts involved sample practice paragraphs and essays, first draft and second draft assessment papers since students had only two assessments during the whole semester. In so doing, 90 texts were obtained from the process of random selection from the students' portfolios. The criteria used by the researcher to select texts were the following: first the text had to be a paragraph or an essay; second, it should be a practice paper or assessment one; third, there should be a mixture of writing practice texts, writing assessment first draft texts as well as second draft ones. This was to assure a variety of texts and more contexts for feedback analysis for all teachers in different scenarios.

\section{Results}

\subsection{Results related to the first research question}

The first research question addressed the teachers' beliefs related to the following aspects of WCF: the importance of WCF, the purpose of WCF, the most effective type of WCF, underlying errors instead of their correction, the correction of errors, peer-feedback, one-to-one conferencing, the praise of student work, student valuing teacher feedback, and teacher awareness of students' WCF preferences. Concerning the first aspect of WCF, the results generally indicated that the teachers held a commonly strong belief that providing feedback was important for students and for their learning how to write as well as for their improvement of writing skills. As for the purpose of feedback, the teachers all pointed out that it would serve many purposes for themselves and the students.

Feedback would allow students to know their weak areas and mistakes and learn how to avoid them. It was assumed by teachers that through feedback they could assess the efficiency of their teaching. With regard to the most effective type of WCF, the responses to this were different as different teachers thought of different ways of conveying effective feedback. In relation to the teachers' beliefs about underlining errors instead of putting correction on the writing paper, most of the teachers did not like it because it would not be beneficial to the students at all and it would be misleading for them.

40 
As far as error correction is concerned, teachers differed as some of them thought it was important and others not. In relation to the beliefs about peer-feedback, the majority of the teachers liked it because they thought of the many benefits it involved. With respect to the beliefs about one-to-one conferencing, the teachers thought differently about it in the sense that some teachers considered it worth doing, beneficial and practical, whereas others not. In addition, in terms of praising, all the teachers shared the view that writing praising comments on the students' papers would be extremely useful, beneficial and essential.

As for the teachers' beliefs about whether their students valued their feedback, most of the teachers confirmed that most of their students did value the feedback they received from their teacher and that this could be noticed directly and indirectly from the students' reaction. As a final point, with respect to the teachers' beliefs about their awareness of their students' WCF preferences, this is again another indication of differences in the teachers' beliefs. Some teachers confirmed their awareness of the students' WCF preferences by asking the students what they needed and expected in terms of feedback. However, other teachers never asked their students about that and used their experience and intuition to know about what students would prefer and need for feedback. They discovered their students' preferences through time in the semester and through the work done in class and students' comments during the one-to-one conferencing sessions sometimes.

In summary, based on the analysis of the teacher semi-structured interviews, there was consensus or congruence in the teachers' beliefs about six WCF areas. On the other hand, there was some lack of consensus or incongruence in their beliefs regarding four WCF areas. So, it can be concluded that the teachers' beliefs about WCF had more congruence than incongruence.

\subsection{Results related to the second research question}

The second research question addressed the teachers' practices related to the following aspects of WCF: the identification of errors, the correction of errors, praising, redrafting, the amount of feedback, the explicitness of feedback, and the focus of feedback. The data related to the teachers' actual WCF practices were collected from class observations, student focus groups and student text analysis. To start with, for error identification most teachers underlined errors and used error codes and these feedback practices were applicable to the assessments only and not the practice drafts. Second, with regard to error correction, the findings showed that most teachers would elicit error correction from students first, then they would shift to a whole class correction of errors. Thus, teachers can be divided into two groups: one group would make very few corrections on the students' papers, however another group would do not make any correction. The third WCF practice is related to the writing of praising comments on the writing paper. For this aspect of feedback some differences in the teachers' practices in praising were identified. The teachers can be divided into three groups in this regard: Some teachers fairly wrote praising comments, others provided very few praising comments, and other ones did not include any praising comments in their feedback. As far as redrafting is concerned, the results showed that most teachers consistently would ask their students to redraft their writing works, especially for the assessments drafts and this was confirmed by the text analysis. Regarding the teachers' WCF practice related to the amount of feedback, findings indicated that most teachers equally used a comprehensive feedback (accuracy, punctuation, spelling, ideas and organisation) for the assessment drafts and not for the practice papers, while few of them used a selective feedback (language, ideas and mechanics). Moving to another WCF practice related the explicitness of the feedback, the collected data showed that the majority of teachers would employ an indirect and coded feedback including comments on the students' writings. Now to speak about the teachers' WCF practice with regard to the focus of the feedback, the results concluded that half the teachers would focus on all aspects of writing except task achievement, while the other half focused only on grammar and spelling and did not consider points related to task achievement, organisation, ideas, and content.

In summary, and as mentioned above, the teachers seemed to share the same practices in six feedback aspects, whereas they seemed to have differences in three areas. So, it can be concluded that there were more congruence than incongruence areas in the teachers' practices.

\subsection{Results related to the third research question}

A general partial congruence was found between the teachers' beliefs and actual practices with regard to error identification. The practices from the observation showed that most teachers used underlining or circling, and error coding. 
However, from the text analysis, it was found that not many teachers used coding of the errors. As far as error correction is concerned, the teachers were divided into two groups: some of them believed in the importance of correcting errors and others did not so. In the observations, the findings showed that most teachers would elicit error from the students first, then they would have a whole class error correction and the minority of teachers would correct very few errors. As for the text analysis, it revealed that six teachers would correct very few errors, and three teachers would do not correct errors at all. This can indicate some partial congruence between the beliefs and the practices of the teachers. Now let us consider another aspect of WCF which is praising. All the teachers believed that praising comments were a very good technique which was essential and it was a kind of reward and encouragement that would boost students' confidence. In practice, however, it was different. So, this feedback aspect is an indication of the contradiction between the teachers' beliefs and practices. Another WCF is redrafting and this is also an area of incongruence between what the teachers believed in and what they did in class in practical terms. In terms of the teachers' beliefs and practices relating to the feedback amount, four teachers considered a selective feedback as appropriate, three teachers thought that comprehensive feedback was efficient because the students could learn from their mistakes, and two teachers believed in varying the amount of feedback. The teachers' practices in the observations, however, revealed that most teachers used a comprehensive feedback (just for assessments); but without any giving feedback points or input on practice drafts. The rest of teachers opted for using a selective feedback. Similarly, the text analysis confirmed the findings of the observation. Thus, this is also another area of incongruence between the beliefs and practices of the teachers.

In terms of beliefs and practices related to the feedback explicitness, some teachers thought that it would be better to use a mixture of direct and indirect feedback, but another group of teachers believed in the importance of using indirect feedback only. On the other hand, after observing the teachers, it was found that nearly all the teachers used an indirect and coded feedback, whereas only one teacher used both a direct and an indirect (coded, but no variety of error codes) feedback. As for the findings of the text analysis, it was noticed that most teachers would use an indirect and coded feedback, thus aligning with the findings of the observations. So, with respect to the explicitness of feedback, there was incongruence between the teachers' beliefs and practices. The last aspect of WCF is the feedback focus. As revealed by the interviews, the majority of the teachers believed that they would focus on one area each time because if they focused on all areas, it would be intimidating to the students. In addition, another group of teachers thought that it would be important to focus on everything, especially in assessments drafts, because if not all mistakes were corrected, gaps would remain. During the observations the majority of the teachers focused on everything, while another smaller group of teachers focused on grammar and spelling only. There was uniquely one teacher who focused on grammar, spelling, content and organisation. This aspect of feedback is another area where the teachers' beliefs and practices did not match.

While the findings revealed a great level of congruence and partial congruence between the teachers' beliefs and practices in two areas of feedback which were the identification of errors and the correction of errors, incongruence could be detected in the remaining five areas. So, it can be concluded that there is more incongruence than congruence between the teachers' WCF beliefs and practices.

\section{Discussion}

As mentioned in the results section above there seem to be a number of mismatches between the teachers' beliefs and practices regarding some aspects of WCF and these are related to the writing of praising comments, redrafting, the amount of feedback, the explicitness of feedback and the focus of feedback. This finding corroborates Lee's results (2009) where several areas of incongruence were identified between teachers' beliefs and practices including feedback focus, feedback explicitness, feedback amount, and positive feedback. With regard to the inconsistency in relation to praising or positive feedback, it can be noted that the teachers' beliefs were not reflected in their practices. This can be explained by their concern with the areas of problems and weaknesses that students had.

In this sense, the teachers are considering only one side of students' performance which needs to be addressed. There is also another possible interpretation of teachers' lack of including positive feedback comments and this might the overload of duties they have as well as the time constraints in which they work. That's why they are only limiting themselves to identifying the errors, putting error codes and writing few comments. Ferris et al.'s (1997) study is in line with the findings related to praising of the current study. 
For them, although most L1 and L2 research highlights the importance of praise in developing the students' writing, teachers' positive feedback is scarce. This also confirms Alkhatib's (2015) study which demonstrated that teachers rarely motivate the high- and average- achievers and have never motivated low-achieving ones through praising their writing.

Now to speak about the teachers' incongruence of their beliefs and practices with regard to redrafting, it seems that this WCF area is problematic among the teachers. Their beliefs were not reflected in their practices. This can be attributed to the constraints that they face and the other challenges that they meet while doing their job. These were previously mentioned while reviewing the factors influencing teachers' beliefs and practices. Another example of inconsistency between the teachers' beliefs and practices is the amount of WCF. This is also an area where teachers' practices did not reflect their beliefs. They had a strong belief in the selective approach, but in their practice they used a comprehensive one. This finding may imply that teachers were concerned with the final product of writing rather than the process of writing which would entail helping students to gain self-editing strategies. The finding also indicated the teachers' beliefs in teacher-centred approaches as they did not give students the chance to find out their errors and correct them. The comprehensive approach in giving WCF was commonly used by L2 writing teachers as reported in previous studies (e.g., Lee, 2004, 2008a, 2009; Ferris et al., 2011).

The explicitness of feedback is also another aspect of WCF where the teachers' beliefs and practices were contradictory. The teachers' self-reported practices were different but their actual practices were similar as they used indirect and coded feedback. So, we notice that what the teachers reported doing was not reflected in their actual practices. The teachers' practices regarding the implementation of indirect WCF aligns with the WCF literature (e.g. Storch, 2010; Van Beuningen, 2010; Ferris, 2002) which suggests that the indirect approach correction is more appropriate as it will encourage students to be more reflective and analytical about their errors. This finding of the current study contradicts with Alkhatib's (2015) study which showed that teachers used a combination of direct and indirect WCF and her finding is in line with Ferris et al. (1997) and Lee (2004, 2008). The teachers in the present study justified their use of the indirect feedback by their desire to make their students learn from their mistakes, to think about them and to reflect on them. The mismatch between the teachers' beliefs and practices regarding the explicitness of feedback can be attributed to the teachers' work-load, time constraints, the big number of students in each class (i.e. section), the number of assessments and exhausting curricula.

The last aspect of WCF that demonstrated inconsistency between the teachers' WCF beliefs and practices was the focus of feedback. This seems to support Alkhatib's (2015) study which reported that teachers were divided in their beliefs and practices regarding the focus of WCF, with six of them believing that organisation should be the primary focus of feedback, while the other four believed in the superiority of language form. Such within-group differences between teachers' beliefs were also reported in other studies (e.g., Cohen \& Cavalcanti, 1990; Gharib, 2009; Lockhart, 2008; Lee, 2008a) which indicates that research into teachers' beliefs about WCF may yield similar results with regard to teachers' beliefs about other domains.

Despite the mismatches between the teachers' beliefs and practices listed above, the findings of the present study showed that the teachers' beliefs and practices were greatly congruent regarding error identification and the correction of errors. For error identification, the study showed that what the teachers believed in could be perfectly seen in their practices. This was another area where standardised practices and procedures were observed while WCF was being provided to students. This could be attributed to the teachers' experience and expertise in feedback. It could also explain the great importance that this WCF was allocated by teachers and it could imply that they were aware of their students' needs, preferences and expectations regarding this point. The consistency between the beliefs and practices among teachers regarding this point can be explained by the fact that underling errors and using error codes are considered essential and basic by them and using these tools shows their experience in providing feedback. This can be also attributed to the teachers' knowledge and awareness of their students' needs, preferences and expectations regarding the identification and localisation of errors on the writing paper.

The teachers also had some consistency in their beliefs and practices with respect to error correction. The teachers did not correct all errors on the student papers because they thought that correcting errors for them would not benefit them, thus some teachers would make very few corrections on the paper and others would not correct at all. It is also worth pointing out that most teachers would elicit error correction first from students then they would hold a whole class correction. 
This is line with Lee's (2009) research where teachers tended to correct and locate errors for students but believed that through teacher feedback students should learn to correct and locate their own errors

\section{Conclusion}

The investigation of the mismatches or the inconsistencies between the teachers' beliefs and practices related to WCF can be a springboard for the teachers' professional development. The teachers can be engaged in a meaningful discussion regarding these inconsistencies, and in so doing this may possibly raise their awareness about their beliefs. The same finding of incongruence between the teachers' beliefs and practices also makes it urgent to make the teachers' beliefs explicit in order to detect those beliefs that are detrimental to learning and to challenge and modify them during the course of development. This, however, does not imply that teacher educators have to teach practitioners to change their beliefs and values, but it means that these beliefs need to be understood and explored by thinking about them in a collaboratively critical and reflective way.

Through raising the teachers' consciousness about their beliefs and about responding to student writing, it can further encourage reflection on how teachers' tacit knowledge shapes the way they understand and act upon information in the classroom.

In addition to the critical reflection on the teachers' WCF beliefs, the contradictions between the teachers' beliefs and practices as well as the existence of the challenges that the teachers face in delivering WCF to students as revealed by the current study require training teachers to experiment with a wider array of feedback techniques. Therefore, it is the administrators who should be initiators of calling experts to organize specialised seminars, training sessions and workshops on campus, about writing pedagogy, in general, and WCF, in particular. This recommendation is also supported by some teachers when they were interviewed in the present study. They all pointed out that they would need further training on WCF. Teachers of the writing skills having prior experience and training would reorient themselves to work more effectively with students who have different needs, difficulties, values, and attitudes, than they had experienced previously. This training should help the teachers to promote a student-centred approach to WCF, train the students on self-editing strategy, maintain positive feedback, and provide feedback on specific patterns of errors,

\section{References}

Al-Adawi, H. (2010). A naturalistic context-based study on feedback on Omani EFL undergraduate student writing. Unpublished PhD Thesis, the University of Leeds.

Alkhatib, M. N. (2015). Written corrective feedback at a Saudi university: English language teachers' beliefs, students' preferences, and teachers' practices. Unpublished PhD Thesis, the University of Essex.

Almarza, G. G. (1996). Student foreign language teacher's knowledge growth. Teacher Learning in Language Teaching, 3, 50-78.

Andrews, S. (2003). Teacher language awareness and the professional knowledge base of the L2 teacher. Language Awareness, 12(2), 81-95.

Bai, H. A. \& Ertmer, P. A. (2008). Teacher educators' beliefs and technology uses as predictors of preservice teachers' beliefs and technology attitudes. Journal of Technology and Teacher Education, 1, 93-112.

Basturkmen, H. (2012). A genre-based investigation of discussion sections in research articles in dentistry and disciplinary variation. Journal of English for Academic Purposes, 11(2), 134-144.

Bitchener, J. \& Ferris, D. R (2012).Written corrective feedback in second language acquisition and writing. New York: Routledge.

Borg, S. (1998a). Teachers' pedagogical systems and grammar teaching: A qualitative study. TESOL Quarterly, 32(1), 9-38.

Borg, S. (1999a). Studying teacher cognition in second language grammar teaching. System, 27(1), 19-31.

Borg, S. (1999b). The use of grammatical terminology in the second language classroom: A qualitative study of teachers' practices and cognitions. Applied Linguistics, 20(1), 95-126.

Borg, S. (2001). Self-perception and practice in teaching grammar. ELT journal, 55(1), 21-29.

Borg, S. (2003). Teacher cognition in language teaching: A review of research on what language teachers think, know, believe, and do. Language Teaching, 36, 81-109.

Borg, S. (2006). Teacher cognition and language education: Research and practice. London; New York: Continuum. 
Borg, S. (2009). English language teachers' conceptions of research. Applied Linguistics, 30, (3), 358-388,

Braun, V. \&. Clarke, V. (2006).Using thematic analysis in psychology. Qualitative Research in Psychology, 3(2), $77-101$.

Brookhart, S. M. (2003). Developing measurement theory for classroom assessment purposes and uses. Educational Management: Issues and Practice, 22(4), 5-12.

Cardelle M. \& Corno, L. (1981).Effects on second language learning of variations in written feedback on homework assignments. TESOL Quarterly, 15(3), 251-261.

Carless, C. (2006). Differing perceptions in the feedback. Studies in Higher Education, 31(2), 219-233.

Christ, T. W. \& Makarani, S. A. (2009). Teachers' attitudes about teaching English in India: An embedded mixed methods study. International Journal of Multiple Research Approaches, 3(1), 73-87.

Clark, C.M. \& Peterson, P.L (1986). Teacher's thought processes. In M. C. Wittrock (Ed.), Handbook of research on teaching. (pp. 255-296). New York: Macmillan.

Cohen, A.D., \& Cavalcanti, M.C. (1990). Feedback on compositions: Teacher and student verbal reports. In B. Kroll (Ed.), Second language writing: Research insights for the classroom (pp. 155-177). Cambridge: Cambridge Univ. Press.

Fang, Z. (1996). A review of research on teacher beliefs and practices. Educational Research, 38(1), 47-65.

Farrell, T. S. \& Kun, S.T. (2008).Language policy, language teachers' beliefs, and classroom practices. Applied Linguistics, 29(3), 381-403.

Ferris, D. R. (2002).Treatment of error in second language writing classes. Ann Arbor, MI: University of Michigan Press.

Ferris, D. R., Pezone, S., Tade, C., \& Tinti, S. (1997). Teacher commentary on student writing: Descriptions and implications. Journal of Second Language Writing, 6, 155-182.

Ferris, D. R., Liu, H., \& Rabie, B. (2011). The job of teaching writing: Teacher views on responding to student writing. Writing and Pedagogy, 3, 14-37.

Feryok, A. (2008). An Armenian English language teacher's practical theory of communicative language teaching. System, 36(2), 227-240.

Foss, D. H. \& Kleinsasser, R. C. (1996).Preservice elementary teachers ${ }^{`}$ views of pedagogical and mathematical content knowledge. Teaching and Teacher Education, 12(4), 429-442.

Gharib, S. T. (2009). Discovering the nature of EFL teachers' beliefs and their relationships to classroom practices in a Syrian secondary school context. Unpublished $\mathrm{PhD}$ thesis, University of Essex.

Hiep, P. H. (2007). Communicative language teaching: Unity within diversity. ELT journal, 61(3), 193-201.

Hyland, K. \& Hyland, F. (2006).Feedback in second language writing: Contexts and issues. Cambridge: Cambridge University Press.

Johnson, K. E. (1992). The relationship between teachers' beliefs and practices during literacy instruction for nonnative speakers of English. Journal of Reading Behaviour, 24(1), 83-108.

Karavas-Doukas, E. (1996). Using attitude scales to investigate teachers' attitudes to the communicative approach. ELT Journal, 50(3), 187-98.

Kennedy, C. (1988). Evaluation of the management of change in ETL projects. Applied Linguistics, 9, 329-342.

Kennedy, C., \& Kennedy, J. (1996). Teacher attitudes and change implementation. System, 24(3), 351-360.

Kulhavy, R. W. (1977). Feedback in written instruction. Review of Educational Research, 47(1), 211-232.

Lee, I. (2004). Error correction in L2 secondary writing classrooms: The case of Hong Kong. Journal of Second Language Writing, 13(4), 285-312.

Lee, I. (2008a). Understanding teachers' written feedback practices in Hong Kong secondary classrooms. Journal of Second Language Writing, 17(2), 69-85.

Lee, I. (2009). Ten mismatches between teachers' beliefs and written feedback practice. ELT Journal, 63, 13-22.

Lee, I. (2013). Research into practice: Written corrective feedback. Language Teaching, 46(1), 108-119.

Lin, H. L., Gorrell, J., \& Silvern, S. B. (1999). Taiwan early childhood pre-service teachers' professional beliefs. Journal of Research in Childhood Education, 15(2), 242-255.

Lockhart, C. (2008). Teachers' beliefs about writing in Hong Kong secondary schools. Retreived from doi: http://sunzi.lib.hku.hk/hkjo/view/10/1000107.

Lu, J. (2003). The Evolving contributions in international strategic management research. Journal of International Management, 9, 193-213. 
Magno, C. \& Amarles, A. (2011). Teachers' feedback practices in second language academic writing classrooms. The International Journal of Educational and Psychological Assessment, 6(2), 22-30.

Montgomery, J. L. and Baker, W. (2007). Teacher-written feedback: Student perceptions, teacher self-assessment, and actual teacher performance. Journal of Second Language Writing, 16, 82-99.

Mubarak. (2013). Corrective feedback in L2 writing: A study of practices and effectiveness in the Bahrain context. Unpublished $\mathrm{PhD}$ Thesis, the University of Sheffield.

Munby, H. (1984). A qualitative approach to the study of a teacher's beliefs. Journal of Research in Science Teaching, 21(1), 27-38.

Oppenheim, A. N. (1992). Questionnaire design, interviewing and attitude measurement. London: Bloomsbury Publishing.

Pajares, M. F. (1992). Teachers, beliefs and educational research: Cleaning up a messy construct. Review of Educational Research, 62(3), 307-332.

Phipps, S. \& Borg, S. (2009). Exploring tensions between teachers' grammar teaching beliefs and practices. System, 37(3), 380-390.

Reichelt, M. (1999). Toward a comprehensive view of L2 writing: Foreign language writing in the U.S. Journal of Second Language Writing, 8(2), 181-204.

Richards, J. C. (1996). Teachers' maxims in language teaching. TESOL Quarterly, 30(2), 281-296.

Richards, K. (2003). Qualitative inquiry in TESOL. Basingstoke: Palgrave Macmillan.

Schwartz, F. \&. White, K. (2000). Making sense of it all: Giving and getting online course. In K. W. Weight (Ed.), The online teaching guide: A handbook of attitudes, strategies, and techniques for the virtual classroom (pp. 57-72). Boston: Allyn and Bacon

Storch, N. (2010). Critical feedback on written corrective feedback research. International Journal of English Studies, 10 (2), 29-46.

Van Beuningen, C. G. (2010). Corrective feedback in L2 writing: Theoretical perspectives, empirical insights, and future directions. International Journal of English Studies, 10(2), 1-27. 